\title{
High-yield Production of Scutellaria Radix Flavonoids (Baicalein, Baicalin and Wogonin) by Liquid-culture of Scutellaria baicalensis Root-derived Cells
}

\author{
Takashi Ohtsuki $^{*}$, Mika Himeji ${ }^{1}$, Harumi Fukazawa ${ }^{1}$, Miho Tanaka $^{1}$, Hisako Yamamoto ${ }^{2}$ \\ and Akio Mimura ${ }^{1}$ \\ ${ }^{1}$ Department of Biotechnology; Faculty of Engineering, University of Yamanashi; 4-3-11; Takeda; Kofu-shi; \\ Yamanashi 400-8511 - Japan. ${ }^{2}$ School of Pharmacy; Hokuriku University; Ho-3, Kanagawa-machi; Kanazawa; \\ Ishikawa 920-1181 - Japan
}

\begin{abstract}
Production of baicalein, baicalin and wogonin by liquid culture of Scutellaria baicalensis cells derived from the plant root was studied. The maximum production obtained were $119 \mathrm{mg} / \mathrm{L}$ of baicalein at two week, $1372 \mathrm{mg} / \mathrm{L}$ of baicalin at eight week, and $14 \mathrm{mg} / \mathrm{L}$ of wogonin at two week. In addition, the production of baicalin was drastically increased to $1000 \mathrm{mg} / \mathrm{L}$ level at 3-week culture, and the extremely high production rate (339 $\mathrm{mg} / \mathrm{L} \bullet$ week) was obtained. In the comparison of total antioxidative activities among baicalein, baicalin and wogonin, evaluated by thiocyanate method, it was suggested that the location of hydroxyl groups both at 5- and 6-position contributed to enhancement of radical scavenging activity, and/or methoxylation at 8-position diminished the activity. The possibility of utilizing these flavonoids for natural antioxidants and medicine is also discussed.
\end{abstract}

Key words: Antioxidant, flavonoids, liquid culture, high-yield production, Scutellaria baicalensis

\section{INTRODUCTION}

Scutellaria Radix (wogon) is the dried root of Scutellaria baicalensis and has been used as a traditional Chinese medicine to treat allergic and inflammatory diseases in Japan and China (Tang and Eisenbrand, 1992). The pharmacologic actions of Scutellaria Radix such as reduction of blood pressure and suppression of allergic actions have been studied (Kimura et al., 1981; Sekiya and Okada, 1982). The major components of Scutellaria Radix are baicalein (5,6,7trihydroxyflavone), baicalin (baicalein 7-D- $\beta$ glucronate) and wogonin (5,7-dihydroxy-8methoxyflavone). These flavonoids are wellknown natural antioxidants (Gao et al., 2001;
Shieh et al., 2000). However, total antioxidative activities evaluated by general method, linoleic acid emulsion system, have not been reported. On other hand, various physiologic activities of these flavonoids have been studied. The inhibitory effects of baicalein and baicalin on expansion of human viruses (Bayer et al., 1992; Wu et al., 1995), and a protective effect of baicalin on renal cell injury (Yokozawa et al., 1999) have been reported. It was also reported that baicalein, baicalin and wogonin showed suppression activity against the production of nitric oxide/prostaglandin $\mathrm{E}_{2}$ (Chen et al., 2001; Chi et al., 2001) and proliferation of cancer cells (Chan et al., 2000; Chen et al., 2002; Matsuzaki et al., 1996; Okita et al., 1993; Yano et al., 1994).

\footnotetext{
* Author for correspondence: tohtsuki@ab11.yamanashi.ac.jp
} 
Considering the industrial production of $S$. baicalensis-derived flavonoids for medical use, production yield is still low and the product cost is high. To increase the production of flavonoids by cultivation of $S$. vaicalensis cells, several trials in vitro using callus cultures and Agrobacteriuminduced hairy root cultures have been reported (Hirotani et al., 1998; Stojakowska and Malarz, 2000; Yamamoto et al., 1986; Yamamoto, 1991). However, the production of flavonoids by liquid culture of $S$. baicalensis cells has not been studied. In this study, we report the productivity of Scutellaria Radix flavonoids by liquid culture of $S$. baicalensis cells. In addition, the total antioxidative activities of baicalein, baicalin and wogonin were also determined in linoleic acid emulsion system.

\section{MATERIALS AND METHODS}

\section{Culture of $S$. baicalensis cells}

Cell culture established from the root of $S$. baicalensis Georgi was kindly provided from Dr. Hisako Yamamoto, School of Pharmacy, Hokuriku University. A modified Murashige-Skoog medium was used for liquid culture of the cells. The composition of the medium was $1.65 \mathrm{~g} / \mathrm{L} \mathrm{NH}_{4} \mathrm{NO}_{3}$, $1.9 \mathrm{~g} / \mathrm{L} \mathrm{KNO}_{3}, 0.44 \mathrm{~g} / \mathrm{L} \mathrm{CaCl} \mathrm{Ca}_{2} \cdot 2 \mathrm{H}_{2} \mathrm{O}, 0.37 \mathrm{~g} / \mathrm{L}$

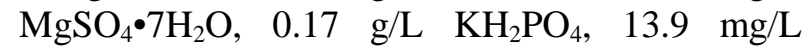
$\mathrm{FeSO}_{4} \bullet 7 \mathrm{H}_{2} \mathrm{O}, 18.65 \mathrm{mg} / \mathrm{L}$ EDTA $\bullet \mathrm{Na}_{2}, 11.15 \mathrm{mg} / \mathrm{L}$ $\mathrm{MnSO}_{4} \cdot 4 \mathrm{H}_{2} \mathrm{O}, 4.3 \mathrm{mg} / \mathrm{L} \mathrm{ZnSO}_{4} \cdot 7 \mathrm{H}_{2} \mathrm{O}, 12.5 \mu \mathrm{g} / \mathrm{L}$ $\mathrm{CuSO}_{4} \cdot 5 \mathrm{H}_{2} \mathrm{O}, 125 \mu \mathrm{g} / \mathrm{L} \quad \mathrm{Na}_{2} \mathrm{MoO}_{4} \cdot 2 \mathrm{H}_{2} \mathrm{O}, 12.5$ $\mu \mathrm{g} / \mathrm{L} \mathrm{CoCl}{ }_{2} \cdot 6 \mathrm{H}_{2} \mathrm{O}, 415 \mu \mathrm{g} / \mathrm{L} \mathrm{KI}, 3.1 \mathrm{mg} / \mathrm{L} \mathrm{H}_{3} \mathrm{BO}_{4}$, $0.5 \mathrm{mg} / \mathrm{L}$ nicotinic acid, $0.1 \mathrm{mg} / \mathrm{L}$ thiamine $\cdot \mathrm{HCl}$, $0.5 \mathrm{mg} / \mathrm{L}$ pyridoxin $\cdot \mathrm{HCl}, 2 \mathrm{mg} / \mathrm{L}$ glycine, $0.9 \mathrm{~g} / \mathrm{L}$ myo-inocitol, $50 \mathrm{~g} / \mathrm{L}$ maltose, $10 \mu \mathrm{M}$ indolacetic acid, $10 \mu \mathrm{M}$ kinetin ( $\mathrm{pH}$ 5.6). Cells were maintained with $110 \mathrm{ml}$ of the medium in $300 \mathrm{ml}$ flask at $25{ }^{\circ} \mathrm{C}$ on a rotary shaker at $100 \mathrm{rpm}$ in a dark condition. Subculture was conducted every two weeks by transferring $10 \mathrm{ml}$ of the culture to a $100 \mathrm{ml}$ of fresh medium.

\section{Extraction and analysis of flavonoids produced from cultured $S$. baicalensis cells}

Cells of $S$. baicalensis were cultivated as same method as in subculture, and the cells were harvested by filtration every week. Ten mililiter of the culture was separately filtered and the harvested cells were completely dried at $70{ }^{\circ} \mathrm{C}$ for the determination of dry cell weight. The rest of culture $(100 \mathrm{~mL})$ was also filtered and flavonoids were extracted from the cells with absolute methanol and $80 \%$ methanol $(200 \mathrm{~mL}$ twice in each extraction). The filtrate of extracts $(800 \mathrm{~mL})$ was mixed and dried completely by evaporation, and resuspended in absolute methanol.

The flavonoids were quantified using HPLC. The total amount of flavonoids contained in the extract from S. baicalensis was calculated as baicalinequivalent, since baicalin was the major flavonoid contained in the extract. Contents of baicalein, baicalin and wogonin were evaluated using pure chemicals (Wako Pure Chemical Industries, Japan) as external standards. A CapcellPak $\mathrm{C}_{18}(4.6 \mathrm{~mm} \emptyset$ x $250 \mathrm{~mm}$, Shiseido, Japan) column was used for HPLC separation. Elution was performed at 1 $\mathrm{mL} / \mathrm{min}$ with $60 \quad \% \quad$ methanol/40 $\quad \% \quad 0.1 \quad \mathrm{M}$ phospholic acid, and the flavonoids were detected by absorbance at $280 \mathrm{~nm}$. Sugar content in the culture supernatant was determined as glucose equivalent by phenol-sulfuric acid method (Ashwell, 1966).

\section{Determination of lipid peroxidation inhibition activities of flavonoids}

The total antioxidant activities of $S$. baicalensisproduced flavonoids were evaluated by the modified thiocyanate method in linoleic acid emulsion system (Mathew and Abraham, 2006). Briefly, $0.1 \mathrm{~mL}$ of flavonoid solution $(5 \mathrm{mM}$ of baicalein, baicalin, quercetin or wogonin purchased from Wako Pure Chemical Industries, Japan, dissolved in methanol), $0.1 \mathrm{~mL}$ of 0.2 $\mathrm{mg} / \mathrm{mL} L$-ascorbic acid as peroxidation mediator and $0.1 \mathrm{ml}$ of absolute methanol were added to 9.8 $\mathrm{mL}$ of linoleic acid emulsion. For a control experiment without addition of flavonoid, $0.1 \mathrm{~mL}$ of $75 \%$ methanol was added instead of flavonoid solution. The linoleic acid emulsion was prepared by mixing $0.5 \mathrm{~mL}$ of linoleic acid to $355 \mathrm{~mL}$ of 10 $\mathrm{mM}$ sodium phosphate buffer ( $\mathrm{pH}$ 7.4) containing $5 \mathrm{~g}$ of sodium dodecyl sulfate as an emulsifier. A $0.5 \mathrm{~mL}$ aliquot of the mixed sample was divided for determination of initial peroxidation degree, and the rest of sample was incubated at $37{ }^{\circ} \mathrm{C}$ to accelerate the oxidation. To determine the peroxidation degree, $9.1 \mathrm{~mL}$ of $75 \%$ methanol, 0.2 $\mathrm{mL}$ of $30 \%$ ammonium thiocyanate and $0.2 \mathrm{~mL}$ of $20 \mathrm{mM} \mathrm{FeCl}_{2}$ (in $3.5 \% \mathrm{HCl}$ ) were added to $0.5 \mathrm{ml}$ of the sample, and the mixture was vortexed. The absorbance at $500 \mathrm{~nm}$ was measured at $3 \mathrm{~min}$ after mixing. The degree of lipid peroxidation was determined at every $24 \mathrm{~h}$-incubation. The data are the averages of duplicate analyses. The inhibition 
of lipid peroxidation (LPI) was calculated by the following equation:

LPI $(\%)=100-\left[\left(A_{1} / A_{0}\right) \times 100\right]$

where $A_{1}$ was the absorbance at $500 \mathrm{~nm}$ in the presence of sample and $A_{0}$ was the absorbance of the control.

\section{RESULTS AND DISCUSSION}

\section{Production of flavonoids by liquid culture of $S$.}

\section{baicalensis}

Production of flavonoids by liquid culture of $S$. baicalensis cells was investigated. As is shown in
Fig. 1, pH of the medium was not so changed. The cells were grown for two weeks (13.7 g dry cell weight/L) with consumption of sugars (mainly maltose) and the quantity of total flavonoid in cells reached $143 \mathrm{mg}$ baicalin-eqivalent/g dry cell weight in first week.

The changes of amounts of major flavonoids baicalein, baicalin and wogonin were also investigated in 5-week and 10-week periods (Figs. 1 and 2 ). It was shown that $60-70 \%$ of flavonoids was baicalin, and that the amounts of baicalein and wogonin were low in comparison with the amount of baicalin.

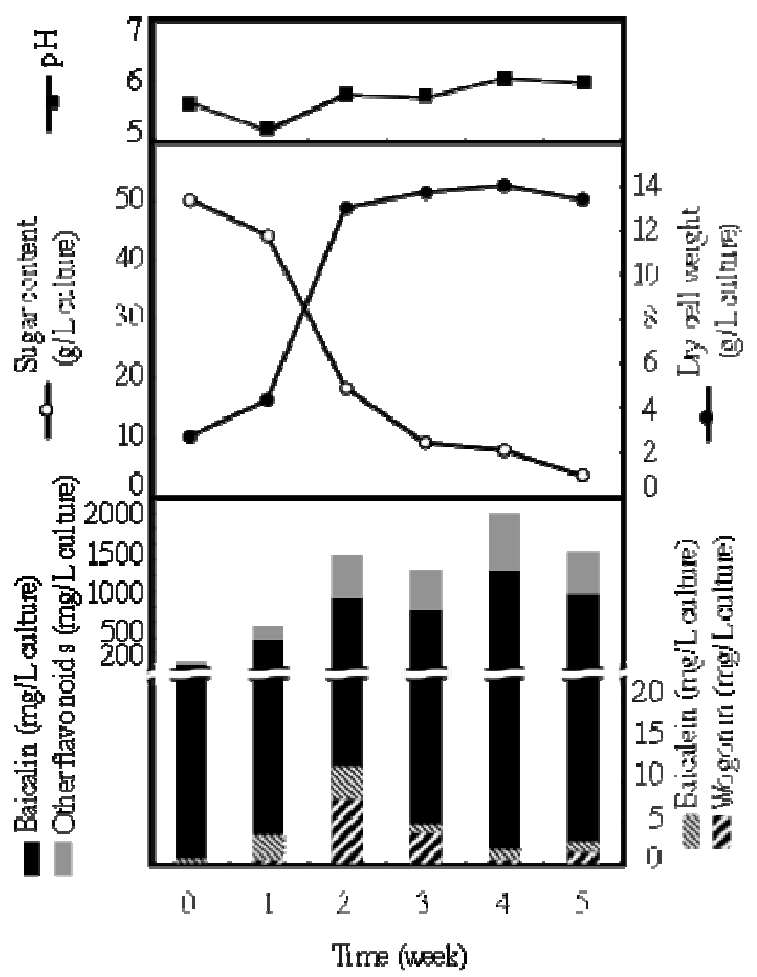

Figure 1 - Cell growth and flavonoid production by liquid cell culture of S. baicalensis. Content of flavonoids except baicalein, baicalin and woginin is indicated as 'other flavonoids' as baicalin equivalent.

The maximum production of baicalein, baicalin and wogonin were 119,1372 and $14 \mathrm{mg} / \mathrm{L}$ culture at two, eight and two week-culture, respectively (Fig. 2). The production of baicalin was constitutively high after the cell growth reached stationary phase (3-week to 10-week culture) which showed that a longer-term (more than three weeks) cultivation was necessary to obtain high amount of baicalin, in contrast with 2-week culture being suitable to harvest baicalein and wogonin. However, increase in production of baicalin at 3week was drastic (Fig. 2) with extremely high productivity (339 $\mathrm{mg} / \mathrm{L} \cdot$ week). This was an advantageous point for industrial application. 


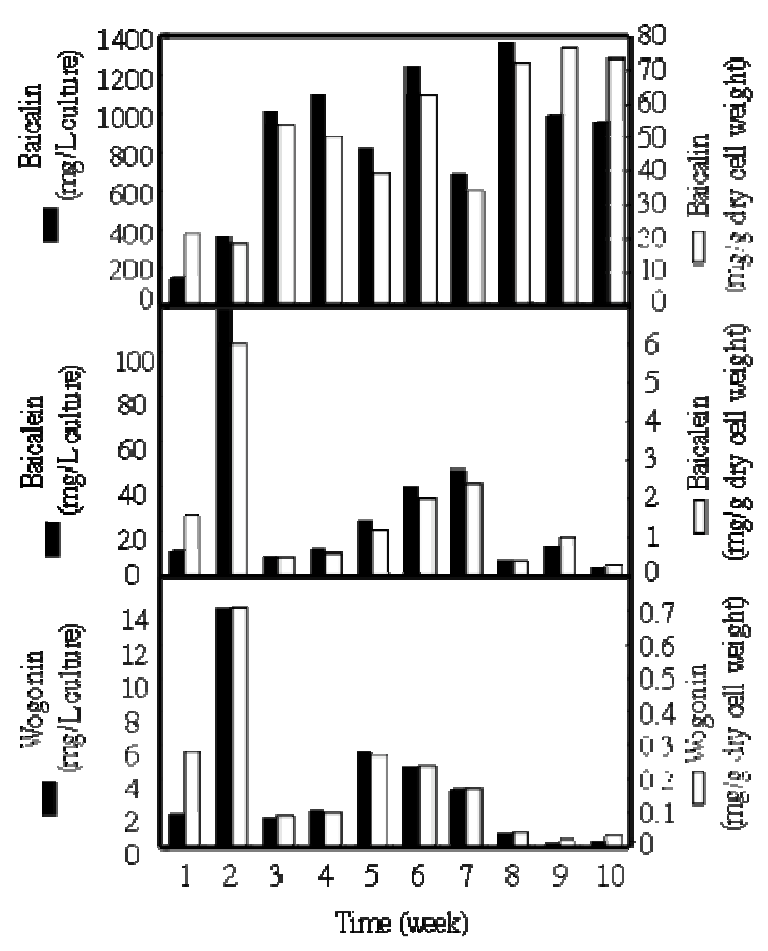

Figure 2 - Production and quantity of baicalein, baicalin and wogonin in liquid cell culture of $S$. baicalensis during 10-week culture period.

Baicalin was produced with extremely high content (maximum $76.5 \mathrm{mg} / \mathrm{g}$ dry cell weight at 8week culture), while baicalein and wogonin were produced with $6 \mathrm{mg} / \mathrm{g}$ dry cell weight at 2-week culture and $0.7 \mathrm{mg} / \mathrm{g}$ dry cell weight at 2 -week culture, respectively (Fig. 2). In other studies of flavonoid production by root-derived cells of $S$. baicalensis, Hirotani et al. (1998) reported that the callus tissue produced $2 \mathrm{mg}$ baicalein/g dry cell weight and $6 \mathrm{mg}$ baicalin/g dry cell weight in 3week culture. Stojakowska and Malarz (2000) achieved $70 \mathrm{mg}$ baicalein/g dry cell weight and 19 $\mathrm{mg}$ wogonin/g dry cell weight of production in 3week culture using Agrobacterium rhizogenestransformed hairy root culture cells. By culturing in the present liquid condition, the culture period to obtain the maximum production of baicalein and wogonin was shortened. Furthermore, it should be noteworthy that the culture condition in this study was good for baicalin, and the production and quantity was drastically increased in comparison with previous works. Achievement of high production of all three flavonoids was considered to be difficult since baicalein, baicalin and wogonin were derivatives from same flavonesynthesis pathway.

\section{Lipid peroxidation inhibition activities of flavonoids}

Figure 3 shows inhibition of lipid peroxidation by $S$. baicalensis-producing flavonoids. In the control experiment with the addition of strong antioxidant quercetin, peroxidation of linoleic acid was completely inhibited by the addition of $5 \mathrm{mM}$ solution. It was shown that the inhibition activity of baicalein was not at all inferior to the activity of quercetin (Fig. 3). In the S. baicalensis-producing flavonoids, baicalein showed higher activity than baicalin, and wogonin showed the lowest activity (Fig. 3). By contrast, Shieh et al. (2000) reported that the order of activity on xanthine oxidase inhibition was baicalein > wogonin > baicalin, whereas the activity on cytochrome c reduction was baicalin > wogonin > baicalein. Considering the present results with baicalein and baicalin, the lower activity observed in baicalin suggested that a disappearance of 7-hydroxyl group by glucosylation weakened the radical-scavenging power of the compound. Shirai et al. (2001) reported that the introduction of a glucuronide group to the 3-position contributed to an increase of affinity toward lipid, resulting decrease of the antioxidative activity. The effect of glucosylation 
of hydroxyl group at 7-position on affinity toward lipid was studied by van Dijk et al. (2000), and it was shown that the glucosylation at 7-position resulted in increase of affinity. From this viewpoint, the lower antioxidative activity of baicalin was considered as that the real baicalin molecules involved in radical scavenging was decreased by higher affinity of baicalin toward lipid micelle than that of baicalein in linoleic acid emulsion system.

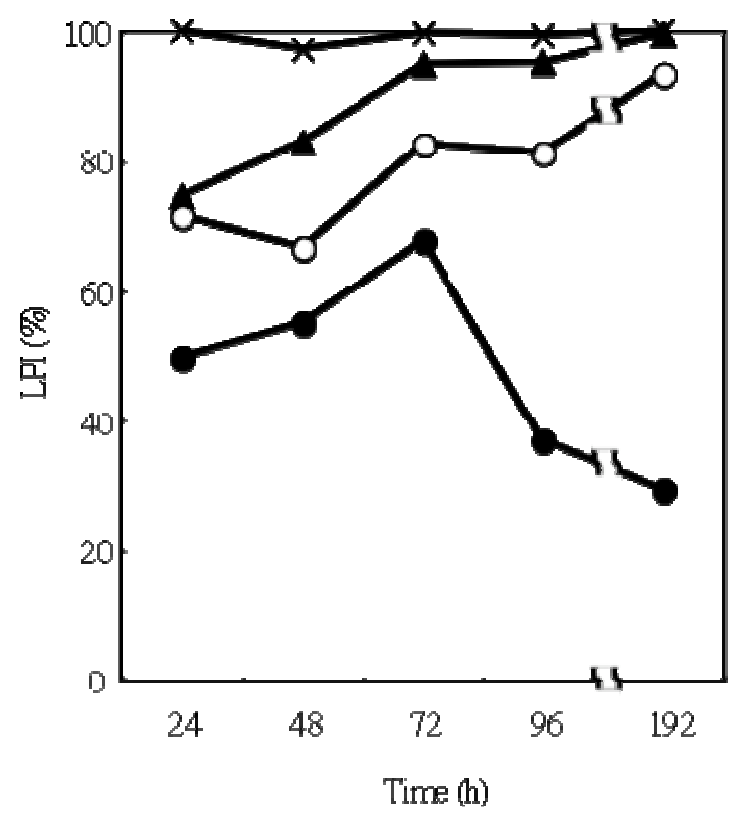

Figure 3 - Inhibition of lipid peroxidation (LPI) of S. baicalensis-producing flavonoids determined by thiocyanate method. Time $(\mathrm{h})$ indicates incubation period for peroxidation of linoleic acid. Symbols; $(\boldsymbol{\Delta})$ baicalein, $(\bigcirc)$ baicalin, $(\bigcirc)$ wogonin and $(\chi)$ quercetin.

The significance of location both of 5- and 6hydroxyl groups in radical scavenging was suggested by drastic decrease of the activity observed in wogonin (Fig. 3). Although quercetin is a flavonol hydroxylated at 5,7-position as same as wogonin, its strong antioxidative activity is generated by the presence of 3', 4'-hydroxyl groups (Cao et al., 1997). Cao et al. (1997) suggested that the methoxylation weakened antioxidative activity of flavonoid, therefore methoxylation at 8-position would be concerned with the activity of wogonin. Interestingly, the degree of LPI by wogonin was turned to decrease after 72-h incubation, in contrast to successive increase of other flavonoids (Fig. 3). This indicated that the antioxidative effect exhibited by wogonin molecule disappeared after 72-h incubation, which would be caused by continuous attack of reactive oxygen species. Considering the result that LPI of baicalein increased after 72-h incubation (Fig. 3) and comparing structures between baicalein and wogonin, disappearance of 'sustainable' antioxidative activity in wogonin would also be concerned with methoxylation at 8-position.

\section{The overview on utilization of $S$. baicalensis- producing flavonoids}

The antioxidative activities of baicalein and baicalin observed in the present study were considered to be activities for scavenging superoxide radical before attacking linoleic acid micelle. This speculation would be supported by the results of Shieh et al. (2000) demonstrating that baicalein and baicalin had strong activities on eliminating the superoxide radical and had no significant effect on scavenging hydroxyl radical. The results obtained in linoleic acid emulsion system (Fig. 3) indicated that baicalein and baicalin were applicable as natural antioxidant, e.g. for cooking oil. Since these flavonoids also have 
other function such as antiinflammatory and anticancer activities, it is possible to develop new 'functional food' contributing to complementary and alternative medicine (CAM).

In this study, drastic increase of flavonoid production in S. baicalensis cells, especially for baicalin, was achieved by liquid culture method. In chemical synthesis of baicalein and wogonin, the production method has been proposed (Huang et al., 2003). On the contrary, baicalin is a glucosylated derivative of baicalein and thus highyield production by chemical process is difficult. In the case of production of baicalein, baicalin and wogonin from field-cultured plant, extraction and purification processes take too much time and the product (flavonoids) become expensive. In this point, liquid culture method is ideal for industrial production of these flavonoids because the operation is manageable and the productivity is high. In addition, baicalein can be obtained easily by deglucosylation of baicalin, therefore, the highyield production of baicalin is significant. Considering the industrial application, the results obtained in the present study indicated the important information for the development of efficient production process of baicalin.

In the comparison of properties among baicalein, wogonin and baicalin production, the production of baicalein and wogonin was drastically increased in initial two weeks, and the increase of baicalin production was followed (Fig. 2). It should be noted that slight increases of baicalein/wogonin contents in 5-7 week cultures seemed to be correlated with decrease of baicalin content in same period though the accumulated levels between baicalein/wogonin and baicalin were extremely different (Fig. 2). There are a few reports of metabolic pathway for baicalein, baicalin and wogonin. Hirotani et al. (2000) reported that hairy root culture cells of $S$. baicalensis expressed UDP-glucose: baicalein 7$O$-glucosyltransferase. Their results indicated that baicalein was a precursor metabolite of baicalin synthesis, and it was suggested that the synthesis of baicalein and/or wogonin would affect the accumulation of baicalin in $S$. baicalensis cells.

In human cell lines, the proliferation of bladder cancer cells and hepatoma cells were known to be suppressed by baicalein, baicalin and wogonin (Chang et al., 2002; Ikemoto et al., 2000). Interestingly, in the present work the different effects between the cancer cell lines and normal diploid cell line were observed by the addition of baicalein, baicalin and wogonin (Himeji et al., 2007). Baicalein and baicalin affected cell proliferation in both cancer cell lines and normal diploid cell line. However, wogonin did not affect the proliferation of normal fetal lung diproid cells but did strongly inhibit the proliferation of cancer cells via induction of apoptosis. From these results, it was suggested that dehydroxylation at 6position and/or methoxylation at 8-position were critical for the decrease of antioxidative activity and selectivity of anti-cancer effect, in comparison with the activities and structures of baicalein and baicalin.

Lee et al. (2004) showed that the inhibition of Pglycoprotein 170, a protein involved in multidrug resistance of cancer cells, could be controlled by the substitution of 6- or 7-hydroxyl group by alkoxyl groups, acetoxy groups, or benzyloxy groups, in baicalein. Especially, the alkylation at 6- or 7-position alone or both enhanced the interaction of baicalein with the protein. In addition, hydroxylation of B-ring in flavonoid was effective for the inhibition of phosphatidylinocitol 3-kinase, playing an important role in signal transduction and cell transformation (Agullo et al., 1997). On the other hand, baicalein has been reported as an a-glucosidase inhibitor (Nishioka et al., 1998). Although the activities of baicalin have not been tested, it was expected that the glucosylated form of baicalein would reveal strong inhibition activities against the enzymes described above. Findings obtained in baicalein should be important for modification of baicalin. The investigation to develop superior medicine against the promotion/progression of cancer and postprandial hyperglycemia without adverse effect should be enhanced for prevention of adult diseases based on high-yield production of baicalin.

To use S. baicalensis-producing flavonoids for CAM, achievement of higher production of wogonin is desired. In the study with culture of $S$. baicalensis calli, the possibility that a change of carbon source, e.g. to raffinose, and its concentration in medium might become a cue to increase the production of wogonin, was suggested (Yamamoto, 1991).

\section{CONCLUSIONS}

The results showed excellent production of Scutellaria Radix flavonoids by liquid culture of 
Scutellaria baicalensis cells. The maximum production of baicalein, baicalin and wogonin were 119,1372 and $14 \mathrm{mg} / \mathrm{L}$, respectively. In addition, it was suggested that the location of hydroxyl group and methoxyl group on flavonid ring would affect radical scavenging activities of these flavonoids. It was remarkable that the extremely high production rate at $339 \mathrm{mg} / \mathrm{L} \cdot$ week of baicalin should contribute to the industrial and medical availability of the flavonoid.

\section{REFERENCES}

Agullo, G., Gamet-Payrastre, L., Manenti, S., Viala, C., Rémésy, C., Chap, H. and Payrastre, B. (1997), Relationship between flavonoid structure and inhibition of phosphatidylinositol 3-kinase: a comparison with tyrosine kinase and protein kinase $\mathrm{C}$ inhibition. Biochem. Pharmacol., 53, 1649-1657.

Ashwell, G. (1966), New colorimetric methods of sugar analysis. In: Neufeld EF, Ginsburg V, editor. Methods in Enzymology VIII. New York: Academic Press. pp. 93-95.

Bayer, N. W., Fu, T., Yan, Y. D., Ruscetti, F. W. (1992), Inhibition of human $\mathrm{T}$ cell leukemia virus by the plant flavonoid baicalin (7-glucuronic acid 5,6dihydroxyflavone). J. Infect. Dis., 165, 433-437.

Cao, G., Sofic, E. and Prior, R. L. (1997), Antioxidant and prooxidant behavior of flavonoids: structureactivity relationships. Free Rad. Biol. Med., 22, 749760.

Chang, W. H., Chen, C. H. and Lu, F. J. (2002), Different effects of baicalein, baicalin and wogonin on mitochondrial function, glutathione content and cell cycle progression in human hepatoma cell lines. Planta Med., 68, 128-132.

Chan, F. L., Choi, H. L., Chen, Z. Y., Chan, P. S. and Huang, Y. (2000), Induction of apoptosis in prostate cancer cell lines by a flavonoid, baicalin. Cancer Lett., 160, 219-228.

Chen, Y. C., Shen, S. C., Lee, W. R., Lin, H. Y., Ko, C. H., Shih, C. M. and Yang, L. L. (2002), Wogonin and fisetin induction of apoptosis through activation of caspase 3 cascade and alternative expression of p21 protein in hepatocellular carcinoma cells SK-HEP-1. Arch. Toxicol., 76, 351-359.

Chen, Y. C., Shen, S. C., Chen, L. G., Lee, T. J. F. and Yang, L. L. (2001), Wogonin, baicalin, and baicalein inhibition of inducible nitric oxide synthase and cyclooxygenase- 2 gene expressions induced by nitric oxide synthase inhibitors and lipopolysaccharide. Biochem. Pharmacol., 61, 1417-1427.
Chi, Y. S., Cheon, B. S. and Kim, H. P. (2001), Effect of wogonin, a plant flavone from Scutellaria radix, on the suppression of cyclooxygenase- 2 and the induction of inducible nitric oxide synthase in lipopolysaccharide-treated RAW 264.7 cells. Biochem. Pharmacol., 61, 1195-1203.

Gao, Z., Huang, K. and Xu, H. (2001), Protective effects of flavonoids in the roots of Scutellaria baicalensis Georgi against hydrogen peroxideinduced oxidative stress in HS-SY5Y cells. Pharmacol. Res., 43, 173-178.

Himeji, M., Ohtsuki, T., Fukazawa, H., Tanaka, M., Yazaki, S., Ui, S., Nishio, K., Yamamoto, H., Tasaka, K. and Mimura, A. (2007) Difference of growthinhibitory effect of Scutellaria baicalensis-producing flavonoid wogonin among human cancer cells and normal diploid cell. Cancer Lett., 245, 269-274.

Hirotani, M., Nagashima, S. and Yoshikawa, T. (1998), Baicalin and baicalein productions of cultured Scutellaria baicalensis cells. Nat. Med., 52, 440-443.

Hirotani, M., Kuroda, R., Suzuki, H. and Yoshikawa, T. (2000), Cloning and expression of UDP-glucose: flavonoid 7-O-glucosyltransferase from hairy root cultures of Scutellaria baicalensis. Planta, 210, 1006-1013.

Huang, W.-H., Chien, P.-Y., Yang, C.-H. and Lee, A.-R. (2003), Novel synthesis of flavonoids of Scutellaria baicalensis Georgi. Chem. Pharm. Bull., 51, 339-340.

Ikemoto, S., Sugimura, K., Yoshida, N., Yasumoto, R., Wada, S., Yamamoto, K. and Kishimoto, T. (2000), Antitumor effects of Scutellaria radix and its components baicalein, baicalin, and wogonin on bladder cancer cell lines. Urology, 55, 951-955.

Kimura, Y., Kubo, M., Tani, T., Arichi, S., Ohminami, H. and Okada, H. (1981), Studies on Scutellariae radix. IV. Effects on lipid peroxidation in rat liver. Chem. Pharm. Bull., 29, 2610-2617.

Lee, Y., Yeo, H., Liu, S.-H., Jiang, Z., Savizky, R. M., Austin, D. J. and Cheng, Y.-C. (2004), Increased antiP-glycoprotein activity of baicalein by alkylation on the A ring. J. Med. Chem., 47, 5555-5566.

Mathew, S. and Abraham, T. E. (2006), In vitro antioxidant activity and scavenging effects of Cinnamomum verum leaf extract assayed by different methodologies. Food Chem. Toxicol., 44, 198-206.

Matsuzaki, Y., Kurokawa, N., Terai, S., Matsumura, Y., Kobayashi, N. and Okita, K. (1996), Cell death induced by baicalein in human hepatocellular carcinoma cell lines. Jpn. J. Cancer Res., 87, 170177.

Nishioka, T., Kawabata, J. and Aoyama, Y. (1998), Baicalein, an a-glucosidase inhibitor from Scutellaria baicalensis. J. Nat. Prod., 61, 1413-1415. 
Okita, K., Lin, Q., Murakami, T. and Takahashi, M. (1993), Anti-growth effects with components of Shosaiko-to (TJ-9) on cultured human hepatoma cells. Eur. J. Cancer Prev. 2, 169-176.

Sekiya, K. and Okada, H. (1982), selective inhibition of platelet lipoxugenase by baicalein. Biochem. Biophys. Res. Commun., 105, 1090-1095.

Sherwood, S. W. and Schimke, R. T. (1995), Cell cycle analysis of apoptosis using flow cytometry. Methods Cell. Biol., 46, 77-97.

Shieh, D. E., Liu, L. T. and Lin, C. C. (2000), Antioxidant and free radical scavenging effects of baicalein, baicalin and wogonin. Anticancer Res., 20, 2861-2866.

Shirai, M., Moon, J.-H., Tsushida, T. and Terao, J. (2001), Inhibitory effect of a quercetin metabolite, quercetin 3-O-b-D-glucuronide, on lipid peroxidation in liposomal membranes. J. Agric. Food. Chem., 49, 5602-5608.

Stojakowska, A. and Malarz, J. (2000), Flavonoid production in transformed root cultures of Scutellaria baicalensis. J. Plant Physiol., 156, 121-125.

Tang, W. and Eisenbrand, G. (1992), Chinese Drugs of Plant Origin. Berlin: Springer. p. 919.

van Dijk, C., Driessen, A. J. M. and Recourt, K. (2000), The uncoupling efficiency and affinity of flavonoids for vesicles. Biochem. Pharmacol., 60, 1593-1600.

Wu, X., Akatsu, H. and Okada, H. (1995), Apoptosis of HIV-infected cells following treatment with shosaiko-to and its components. Jpn. J. Med. Sci. Biol., 48, 79-87.
Yamamoto, H., Chatani, N., Watanabe, K. and Tomimori, T. (1986), Effects of carbon sources on the growth and flavonoid formation of Scutellaria baicalensis stem callus cultures. Shoyakugaku Zasshi, 40, 19-25.

Yamamoto, H. (1991), Scutellaria baicalensis Georgi: In vitro culture and the production of flavonoids. In: Bajaj YPS, editor. Biotechnology in Agriculture and Forestry, Vol. 15, Medicinal and Aromatic Plants III. Berlin: Springer-Verlag. pp. 398-418.

Yano, H., Mizoguchi, A., Fukuda, K., Haramaki, M., Ogasawara, S., Momosaki, S. and Kojiro, M. (1994), The herbal medicine Sho-saiko-to inhibits proliferation of cancer cell lines by inducing apoptosis and arrest at the $\mathrm{G}_{0} / \mathrm{G}_{1}$ phase. Cancer Res., 54, 448-454.

Yokozawa, T., Dong, E., Kawai, Y., Gemba, M. and Shimizu, M. (1999), Protective effects of some flavonoids on the renal cellular membrane. Exp. Toxicol. Pathol., 51, 9-14.
Received: August 15, 2007; Revised: June 23, 2008; Accepted: November 05, 2008. 